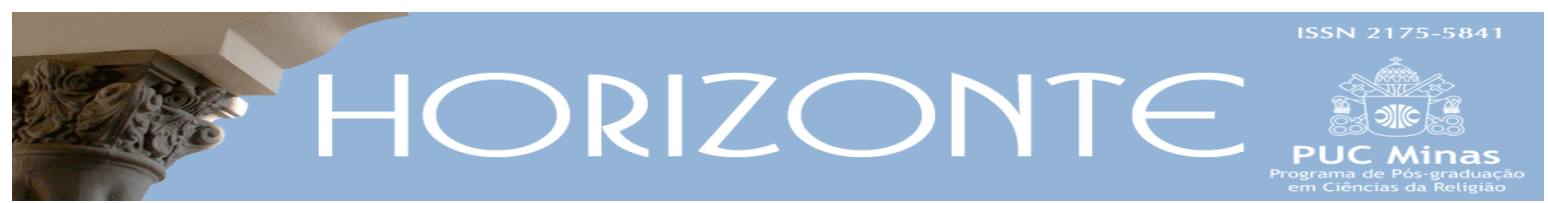

Dossiê: Santuários e Turismo Religioso - Artigo Original ๑응

DOI - 10.5752/P.2175-5841.2018v16n49p88-106

\title{
Turismo religioso e identidade nacional
}

\author{
Religious tourism and national identity
}

Edin Sued Abumanssur*

\begin{abstract}
Resumo
Neste artigo queremos por sob escrutínio o papel dos santuários de devoção popular e sua cria dileta, o turismo religioso, em face da formação da identidade nacional. Afirmamos aqui que o lugar da religião como força de criação identitária é visível e quase que auto evidente no fenômeno moderno das migrações. No entanto, a mesma evidência não se impõe quando focamos os olhos no fenômeno turístico e em especial no turismo religioso que acontece em torno dos santuários nacionais.. Discute ainda a dificuldade que a religião encontra em criar um substrato cultural sobre o qual edificar a identidade brasileira. O Santuário Nacional de Aparecida, o mais emblemático santuário brasileiro tampouco consegue produzir uma narrativa hegemônica na qual os brasileiros possam se reconhecer como tais.
\end{abstract}

Palavras-chave: Religião, Santuários, Turismo Religioso, Identidade Nacional

\begin{abstract}
In this article we want to scrutiny the role of shrines of popular devotion and their most obvious creation, religious tourism, in the face of national identity. We affirm here that the place of religion as a force of identity creation is visible and almost self-evident in the modern phenomenon of migration. However, the same evidence does not apply when we focus on the phenomenon of tourism and especially on religious tourism that takes place around national shrines. We also discusse the difficulty that religion finds in creating a cultural substratum on which to build identity Brazilian The National Shrine of Aparecida, the most emblematic Brazilian shrine, can not produce a hegemonic narrative in which Brazilians can recognize themselves as such.
\end{abstract}

Keywords: Religion, Shrines, Religious Tourism, National Identity

Artigo submetido em 01 de fevereiro de 2018 e aprovado em 19 de abril de 2018.

* Doutor em Ciências Sociais pela PUC-SP e Professor de Sociologia da Religião na PUC-SP. País de origem: Brasil. E-mail: edin@pucsp.br

Horizonte, Belo Horizonte, v. 16, n. 49, p. 88-106, jan./abr. 2018- ISSN 2175-5841 


\section{Introdução}

Todas as formas de mobilidade humana têm por motivação básica o trabalho. Menos o turismo. Em geral, o turismo acontece no polo oposto ao do trabalho. É no tempo do ócio, das férias, do não-trabalho que as pessoas se põem na estrada para buscar aquilo que pensam ser, de fato, a "vida verdadeira", a razão de viver, seja isso o usufruto do tempo ou a devoção ao divino.

Neste artigo pomos sob escrutínio o papel dos santuários de devoção popular e sua cria dileta, o turismo religioso, em face da formação da identidade nacional. Afirmamos aqui que o lugar da religião como força de criação identitária não é tão evidente quando focamos os olhos no fenômeno turístico e em especial no turismo religioso que acontece em torno dos santuários nacionais.

O turismo levanta problemas de largo espectro quando o assunto é a religião. Temas caros como a secularização a constituição das nacionalidades e das identidades nacionais ou locais ganham em complexidade porque o turismo traz para a boca de cena da nossa modernidade globalizada um espelho que obriga a plateia a interpretar e reagir à imagem refletida. O turismo nos põe diante do outro, da sua língua, da sua cultura, da sua religião. E nada melhor que o outro para nos fazer pensar sobre nós mesmos. No entanto, isso não acontece sem dificuldades.

\section{Globalização e turismo}

O turismo é uma dentre as formas de mobilidade humana que só pode ser compreendido em face dos processos modernos de globalização. O turismo impõe o deslocamento espacial e coloca pessoas e coletividades diferentes em contato e interação. Outra forma de mobilidade humana que só pode ser compreendida no mesmo registro dos processos globais é a migração. No entanto, não nos ocuparemos aqui com essa temática. Ela é em si mesma um fenômeno cuja complexidade transcenderia os limites dessa reflexão. Pontuamos apenas as 
relações estreitas mantidas entre a globalização e esses fenômenos contemporâneos de mobilidade.

A ideia de globalização é equívoca e ambígua, mas para este artigo nós nos limitamos aos aspectos culturais desse processo que multiplica os quadros e as fontes de referências identitárias que organizam e dão o sentido de pertença aos indivíduos. ${ }^{1}$

A globalização acontece nos marcos da modernidade que assistiu a emergência do indivíduo como pivô dos processos produtivos com reflexo direto sobre as formas de organização política e cultural que lhe dão sustentação. Globalização e modernidade, ideias irmãs e coextensivas, constituem o pano de fundo para entendermos a emergência desse atual fenômeno turístico.

A globalização invoca, quase que automaticamente, algumas ideias como o rompimento de fronteiras geográficas e econômicas. De fato, os processos econômicos de produção e consumo das coisas, foram os maiores beneficiários desse movimento chamado de globalização. Contraditoriamente a força de trabalho, justamente aquele fator que permite que coisas sejam produzidas e consumidas, é a menos beneficiada por essa globalização disponível.

As barreiras culturais são mais difíceis de analisar porque há dois movimentos concomitantes que agem em sentidos contrários: a globalização desestrutura as culturas locais pela universalização dos costumes, anseios e expectativas ao reduzir os cidadãos à dimensão de consumidores e expô-los a um mercado uniformizado e padronizado para atender aos interesses de um sistema de produção que desconhece os limites dos estados-nação.

A globalização cria espaços de justaposição cultural onde diferentes povos se tocam e interagem, às vezes de maneira conflituosa. São as Zonas Francas, isto é, os

\footnotetext{
${ }^{1}$ Para a discussão mais contextualizada das incidências da globalização sobre as culturas locais, leia-se o capítulo de Enzo Pace (1997, p. 25-42).
} 
espaços sociais que já não podem ser identificados com segurança como pertencentes a esta ou àquela cultura, a este ou a aquele tipo de sociedade ou de economia. Zonas Francas como lugares simbólicos nos quais os indivíduos experimentam a fragilidade das fronteiras simbólicas nos respectivos sistemas a que pertencem. (PACE, 1997, p. 27).

Cada vez mais diminui os espaços para o estranhamento, a surpresa, o abismo. Diante desse tsunami político-cultural-social-econômico que chamamos de globalização, não há muito para onde correr. Em grande medida, o nosso estilo de vida, nossos valores, nossas certezas são dependentes de um mundo cada vez mais padronizado. Mas, justamente por isso, a globalização também provoca a busca pela reafirmação ou reconstrução das identidades nacionais ou locais². Esse é um paradoxo que ainda está por ser entendido. O turismo, e mesmo o turismo religioso, não cooperam necessariamente para a maior aproximação entre povos e culturas. O mais comum é que as diferenças sejam reafirmadas, quase sempre em detrimento das comunidades e locais visitados (KRIPPENDORF, 2001, p. 82).

O turismo foi, sem dúvida, grandemente beneficiado por esse movimento de abertura geral pelo fato de que o trânsito das pessoas significa também o trânsito de moedas, de divisas e, consequentemente, o incremento de economias locais. Embora haja situações como a de Barcelona, que começa a rever negativamente o aporte que o turismo pode trazer para a sua economia, em geral os lugares que têm boa infraestrutura de vida para seus habitantes são os que têm mais condições de aproveitar os fluxos turísticos.

Mas a modernidade incide também sobre o fenômeno religioso e modifica ou acrescenta novas formas de se vivenciar a religião. Há concomitância da vivência religiosa enquanto experiência individual e enquanto experiência comunitária ou coletiva. Para o Ocidente, o critério de aferição da verdade religiosa é baseado no tipo de relação subjetiva com um determinado conjunto de crenças

\footnotetext{
${ }^{2}$ Para uma melhor compreensão sobre as implicações do processo de globalização em marcha e as reações e resistências culturais e religiosas que ele promove e articula, remetemos o leitor a Abdelmalek Sayad (1998) e também a Calhoun; Juergensmeyer; Vanantwerpen (2011).
} 
que alimenta a adesão consciente e o sentimento de posse de uma fé. Nos limites desse tipo de relação, torna-se inadequado falar em pertença religiosa no sentido em que a tradição sociológica opera os conceitos de adesão e conversão. O vetor conceitual se inverte e agora os indivíduos não pertencem mais a uma determinada religião. Agora eles têm (ou não têm) uma religião. Inverteram-se, em nossa modernidade religiosa, as relações entre posse e possuidor. Nesta perspectiva, a religião não é mais o amálgama capaz de transformar uma coleção de indivíduos em uma sociedade. Tampouco seria a religião o elemento identitário de uma comunidade ou nação. Mesmo onde há uma religião majoritária em um território específico, mesmo ali, a relação que o cidadão estabelece com essa religião não é da mesma natureza daquela que em sociedades pré-modernas determinava a pertença ou não a ela. Neste caso, vive-se o primado das seitas em detrimento daquilo que Troeltsch (1931, p. 331) chamou um dia de igreja. Porém, isso não é tudo que se pode dizer ou pensar sobre a religião na modernidade.

Essa mesma modernidade também faz reemergir formas religiosas que se criam superadas por serem vistas como formas arcaicas de religião. São teorias que vêem na religião a força necessária à formação identitária de um povo, característica de sociedades onde prevalece aquilo que Durkheim chamou de solidariedade mecânica. Essa forma “arcaica” de religião está presente e visível nos processos migratórios recentes. Mas o turismo religioso, ao permitir a experiência da alteridade, também cria espaços de reafirmação, fortalecimento e consolidação de uma fé ou tradição religiosa.

Se a religião recoloca em pauta as questões de identidade e nacionalidade, o turismo religioso, em algumas de suas expressões, acode como uma das formas possíveis de promover e fortalecer a adesão religiosa. Não é de hoje que as viagens para destinos religiosos têm servido como forma de reforço catequético na educação da fé. A globalização não vai acabar ou promover a diminuição do ímpeto e da adesão religiosa. Pode ser paradoxal, mas a forma moderna de expressão religiosa abre espaço para vivências “arcaicas” da mesma. A religião, mesmo em 
sua expressão turística, em diferentes situações tem se tornado um dos elementos de resistência ao processo de desenraizamento cultural.

$\mathrm{Na}$ modernidade recente convivem, pois, formas arcaicas e modernas de vivências religiosas. São formas aparentemente antagônicas, mas um olhar mais detido e cuidadoso poderá perceber que elas são produtos do mesmo grande processo de globalização. Essa concomitância de formas distintas de se entender a religião mereceria, por si só, um estudo mais detalhado para se aproximar da grande complexidade que lhe subjaz e que nos impede de reduzi-la aos termos de uma única escola de análise sociológica.

\section{Peregrinação e turismo religioso}

A distinção entre peregrinação e turismo só interessará nos processos diacríticos de acumulação de capital simbólico. Em outras palavras, essa é uma distinção importante para quem participa do jogo, para quem vive a ilusio do campo religioso pesquisado. Para quem olha o fenômeno de fora, como faz a antropologia, por exemplo, a distinção só interessa para a compreensão de como ela é usada pelas partes envolvidas na disputa pelo capital simbólico disponível.

Por turismo religioso podemos entender as visitas que crentes em geral fazem a determinados lugares tidos como possuidores de qualidades especiais no contexto da fé professada. Esse tipo de turismo tem um determinante externo que é o modelo de viagem planificada, popularizada e disponibilizada para grandes contingentes populacionais e tem, também, um determinante interno que diz respeito ao tipo de religião vivida no ocidente moderno. É uma convergência de fatores cuja gênese pode ser traçada na história, mas que não faremos aqui.

Embora o peregrino moderno transcenda as fronteiras dos estudos sobre turismo, é preciso reconhecer que tratar as peregrinações como "turismo religioso" só se tornou possível após o surgimento das massas de trabalhadores que desde a 
revolução industrial vêm conquistando, aos poucos, o direito ao lazer. Essa conquista veio crescendo desde a segunda metade do século XIX, até que, no final do século XX, acreditava-se que estávamos assistindo ao surgimento de uma sociedade de lazer, com menos trabalho e mais tempo de ócio. Tais crenças provaram ser apenas isso: crenças sem fundamentos na realidade. "Os prognósticos otimistas só puderam ser elaborados por aqueles que abraçaram a tese do determinismo tecnológico e se esqueceram de que a base material do capitalismo é capitalista” (LAZZARESCHI, 2001, p. 127-134). A massificação das viagens é determinante para os estudos do turismo moderno. Essa massificação tornou a viagem, antes privilégio de poucos, em algo acessível aos vários tamanhos de bolso e orçamento.

O turismo de massa, como fenômeno social, é coisa típica do século XX. A democratização das viagens implicou na oferta de produtos turísticos administráveis para grandes contingentes populacionais. Os pacotes turísticos baratearam os custos de uma viagem e a tornou acessível a uma boa parcela da população. Mas, turismo de massa não significa apenas a quantidade de gente envolvida em viagens. O volume de pessoas em trânsito impõe aos agentes turísticos a necessidade de dar a esse contingente um tratamento padrão, nivelado, homogeneizado e indiferenciado.

O produto turístico religioso sofre a mesma padronização de oferta do turismo de massas. Deste modo ele pode ser vendido a diferentes grupos sociais de diferentes localidades.

Se a peregrinação religiosa acompanha o homem desde o dia em que ele reconheceu diante de si uma hierofania, o turismo religioso, por sua vez, é fenômeno moderno. Ele é fruto da mesma racionalidade administrativa com a qual as agências de viagens operam qualquer demanda de lazer. As viagens com motivação ou destinação religiosa só vieram a se tornar turismo religioso quando o volume de pessoas envolvidas alcançou uma escala que tornasse economicamente viável o planejamento e os investimentos na área. (ABUMANSSUR, 2003, p. 56). 
Esse ganho de escala do turismo religioso é coisa recente no desenvolvimento do mercado turístico nacional. Até o início dos anos 2000, não havia agência de viagens especializada nesse nicho comercial. As poucas agências que vendiam pacotes com formatação religiosa tinham como destino, quase que exclusivamente, a Terra Santa ou Roma. O grau de especialização das agências surge à medida que pastores e outros líderes religiosos percebem que os membros de suas igrejas são clientes potenciais com perspectivas de bom retorno financeiro para si e para agências. Hoje esses pacotes turísticos cuidam não apenas dos aspectos relacionados ao deslocamento e à hospedagem, mas também das atividades religiosas propriamente ditas. No entanto, para os destinos nacionais esse mercado especializado permanece ainda indigente. $\mathrm{O}$ turismo religioso interno é considerado turismo de pobre, pois é muito comum que as caravanas e romarias sejam organizadas de forma espontânea pelos próprios romeiros ou pelas paróquias. Nesse sentido, muitas das peregrinações e romarias que acontecem no Brasil só não são turismo religioso por falta de interesse econômico dos operadores do mercado turístico.

Mas a peregrinação não se torna turismo religioso apenas pela ação ou tratamento dado a ela pelos agentes e gestores do turismo ou da administração pública. O próprio peregrino moderno comporta-se como um turista à medida que a religião mesma se torna objeto de consumo. Desde a Idade Média, as peregrinações eram, a um só tempo, atos penitenciais e, também, a oportunidade de viagem e diversão para aqueles que possuíam o dinheiro necessário para a jornada, quase sempre realizada em companhia de amigos. Mas, ainda assim, o aspecto penitencial era o motivador da viagem. Mesmo porque a noção de lazer como algo que se opõe ao tempo do trabalho, é própria de uma sociedade organizada em torno das atividades consideradas produtivas. Na modernidade, a peregrinação realizada nos períodos de férias é, ao mesmo tempo, o usufruto desses períodos. Assim é que a maioria das peregrinações aos lugares santos da Europa, Ásia e Oriente Médio, são integradas a pacotes turísticos que incluem vários outros passeios. A religião é apenas mais um elemento que compõe o pacote de férias. 
Há quem busque traçar as fronteiras entre turistas e peregrinos, muitas vezes na intenção de salvar as peregrinações do vórtice das ações empresariais que visam lucrar com a fé alheia (DONELLY, 1992). Essas distinções seriam: 1) os peregrinos percebem uma dimensão interna para a peregrinação, enquanto os turistas estão preocupados apenas com a externalidade da viagem; 2) os peregrinos se comprometem com a jornada e o destino, enquanto os turistas evitam o compromisso pessoal; 3) o foco do peregrino é afetado por sua peregrinação, enquanto o turista busca criar distanciamento de suas experiências; 4) tanto a jornada quanto a chegada são importantes para o peregrino, enquanto que para o turista apenas a chegada ao destino importa; e 5) na peregrinação forma-se uma comunidade de peregrinos, e para o turista isso não é um objetivo. Fica evidente que há algo um tanto forçado nessa tentativa de separar ambas as experiências de mobilidade. No fundo, e após sucessivos questionamentos, essas diferenças não são tão reais nem óbvias e tampouco necessárias. Ao fim e ao cabo a peregrinação e o turismo emergem da mesma insatisfação e do mesmo sentimento de incompletude propiciado pelo desassossego com a mesmice cotidiana.

\section{Turismo religioso e identidade nacional}

Um engano comum nas discussões atuais, marcadas pelo ressurgimento da problemática do estado laico, é desconhecer que a religião tem papel relevante na constituição das nacionalidades, mesmo em sociedades secularizadas, que vai além da articulação da resistência ao desenraizamento cultural provocado pelo processo de globalização, como afirmamos no início desse texto. Nos debates sobre a presença da religião no espaço público, a ideia de estado laico, enquanto um valor conquistado pelas sociedades ocidentais acaba por imprimir um viés apologético que não faz justiça à importância que a religião ainda hoje possui na constituição da cultura das nações.

O tema religião e identidade nacional já foi objeto de diferentes estudos (SACHS, 1988; LUCKMANN, 2014; BELLAH, 1967). No entanto, parece que o 
lugar do turismo religioso tem sido negligenciado nessa equação. É neste momento que nos questionamos sobre o lugar dos santuários de devoção na formação da identidade nacional.

Ao falar de identidade nacional nós acompanhamos as proposições de Stuart Hall que afirma que "as identidades nacionais não são coisas com as quais nascemos, mas são formadas e transformadas no interior da representação" (HALL, 2006, p. 48). Ainda, segundo Hall, a identidade nacional é um discurso que traz e faz sentido para aqueles que com ele se identificam. Identidade nacional é algo imaginado, são memórias e estórias sobre a nação que costuram as diferentes ideias que se tem sobre ela, bem como um passado que possa ser significativo para o presente. A identidade nacional, ou seja, a ideia que uma nação tem si, é algo mutante e mutável, que atende a interesses que podem ser rastreados e que dependem de forças sociais - políticas, econômicas, religiosas - que em um determinado momento conquistam hegemonia no imaginário da população. Identidade nacional é, portanto, uma construção imaginária. Isso não significa que não seja real ou que não tenha força e poder para determinar comportamentos e constituir valores que ordenam e constroem um país.

A identidade de uma nação se firma sobre as narrações que se fazem sobre o seu passado, quase sempre mitificado, que garante certa continuidade temporal. Essas narrativas míticas não só iluminam o presente, mas agregam os indivíduos em uma comunidade de pertencimento e dão a eles um sentido para as suas trajetórias pessoais. No entanto, a identidade nacional é também a síntese de uma hegemonia de poder que atende a interesses suficientemente difusos para não serem identificados como tais. A construção da identidade nacional é a história de uma conquista sobre culturas particulares, é a história de solapamentos de diferenças, a história de uma unificação feita muitas vezes pela força das armas. A formação de uma nação e sua respectiva cultura é uma história de violência simbólica, mas também física. Stuart Hall sugere que, ao invés de pensarmos a cultura ou a identidade nacional como uma coisa unificada, deveríamos pensá-las 
"como um dispositivo discursivo que representa a diferença como unidade e identidade" (HALL, 2006, p. 62). A identidade nacional é, pois, um amálgama produzido por diferentes culturas que interagem com maior ou menor poder de barganha.

Os debates sobre turismo já enfrentaram esse problema sob a ótica da antropologia (BANDUCCI JÚNIOR; BARRETO, 2001). Em grande medida, a experiência turística oferece um ponto de vista que permite ver as identidades culturais em perspectiva analítica. Toda viagem é feita desde o ponto de vista irredutível do viajante. Por outro lado, do ponto de vista do polo receptor, o turista - bem como o migrante - oferece ocasião para análise e, quase sempre, reforço da antinomia entre o "nós" e o "eles". Debate esse extremamente familiar aos etnógrafos. As zonas de contato entre diferentes culturas, etnias ou religiões se tornam uma arena de "diálogo" na qual são encenadas tramas sociais que atendem a interesses em ambos os polos.

No que diz respeito ao turismo religioso que acontece em torno dos santuários de devoção popular no Brasil - Aparecida, Belém, Juazeiro do Norte, Lapa, Iguape e outros - há também a encenação por parte de diferentes atores com seus respectivos interesses produzindo o melhor dispositivo discursivo permitido pela situação.

Esse turismo, romaria ou peregrinação, é espaço de trocas, disputas e negociações de diferentes atores: os próprios romeiros e seus grupos procedentes de diferentes lugares; os residentes no local com seus interesses particulares; os agentes religiosos que procuram trazer a prática devocional para o campo da oficialidade sacramental ou, pelo menos para um campo sob sua influência; os comerciantes que disputam com as autoridades civis e eclesiásticas o direito de permanecerem próximos ao santuário com suas mercadorias. São muitos os personagens que fazem a romaria acontecer. O evento se torna assim uma "arena" de altíssima polissemia para onde convergem os interesses desses personagens. A 
marca, no entanto, dos santuários de devoção popular e que mobiliza os diversos agentes envolvidos nesse tipo de turismo, é o conjunto de mitos e lendas que organizam e justificam a devoção.

A imputação de lugar sagrado, distinto e dotado de poder está imediatamente associada às narrativas míticas a seu respeito. Os relatos que surgem e crescem em torno dessas imagens acentuam o caráter miraculoso, desde a forma como são encontradas até as realizações posteriores dos milagres que sustentam e dão razões para as peregrinações e romarias. (ABUMANSSUR, 2017, p. 112).

Os mitos são recorrentes e obedecem a um padrão composto dos mesmos mitemas: a imagem de Nossa Senhora de Nazaré, encontrada em 1700 por Plácido José de Souza, segundo uma das lendas, vivia fugindo para onde fora achada, indicando assim o local que queria ser adorada. O Bom Jesus de Pirapora, encontrado nas águas do rio Tietê, recusava-se a ser levado para Santana de Parnaíba tornando-se inamovível quando essa era a intenção. O mesmo acontecia com a imagem do Bom Jesus de Iguape, em 1647, que não havia quem conseguisse tirá-la do lugar se a intenção era levá-la para Itanhaém, sede da província. A imagem de Nossa Senhora da Conceição Aparecida, em 1717, da mesma forma fugia de Guaratinguetá e voltava para o porto de Itaguaçú indicando o lugar onde deveriam construir um oratório para ela. Outro mitema recorrente é o lugar social das pessoas para quem a Virgem ou os santos decidem se mostrar. São sempre pescadores, escravos, indígenas, lenhadores, pastores, ou seja, pessoas marginais aos círculos de poder, gente pobre e carente de recursos materiais.

Os grandes santuários brasileiros como o de Aparecida, o de Belém, o de Juazeiro do Norte, o do Bom Jesus da Lapa e vários outros de menor porte surgiram em torno da devoção popular, leiga e sincrética. Esses santuários foram assumidos aos poucos, a partir do século XIX, pelas congregações religiosas que aqui chegavam e que procuraram dar à religiosidade vivida pelo povo um verniz de modernidade e respeitabilidade intelectual. No entanto, os ritos e as crenças populares subsistem sob a batuta do clero erudito. "A despeito da maior presença 
da Igreja, há e ainda surgem por esse Brasil afora, devoções que são próprias das camadas mais pobres e carentes como, por exemplo, a devoção em torno da beata Nhá Chica, de Baependi” (ABUMANSSUR, 2017, p. 111).

Dos santuários brasileiros, o de Aparecida é o que reúne as melhores condições para se tornar, de fato e de direito, como ele mesmo se autoproclama, um Santuário Nacional. Mas não sem problemas.

A Mãe de Deus, Nossa Senhora, mesmo antes da descoberta da imagem no Rio Paraíba, segundo o mito fundante da devoção de Aparecida, já possuía largo curso na religiosidade e no imaginário do brasileiro branco, negro ou pardo. De fato, os acontecimentos de 1717 só podem ser compreendidos tendo como pano de fundo a centralidade de Maria para a fé popular desde a chegada dos portugueses nas terras de Santa Cruz. Conforme o historiador Dilermando Ramos Vieira

O Brasil teve a figura da Mãe de Deus como presença marcante desde o início de sua história, mesmo que não se tratasse de uma fé erudita, mas da transplantada piedade das populações humildes das vilas lusitanas. Esta se mesclaria depois com a sensibilidade indígena e africana, propiciando a formação de uma original religiosidade nos trópicos. (VIEIRA, 2017, p. 47).

A pedra fundamental da atual basílica foi lançada em 10 de setembro de 1946 e a construção mesma foi iniciada em 11 de novembro de 1955. Benedito Calixto projetou-a em formato de uma cruz grega com 4 naves de iguais dimensões. São quase 12 milhões de romeiros que acorrem ao Santuário por ano (SAMPAIO, 2017, p. 163). Para dar acolhida a essa gente toda foi construído também o Centro de Apoio ao Romeiro com centenas de lojas e uma praça de alimentação. A administração do Santuário está a cargo dos Missionários Redentoristas desde o final do século XIX.

Rubem Cesar Fernandes, em um texto de 1988, fez uma análise do Santuário de Aparecida na perspectiva de sua capacidade de sintetizar a identidade brasileira da mesma forma que a Virgem de Guadalupe, no México, ou a Virgem de 
Czestochowa, na Polônia são capazes de congregar nas suas respectivas imagens as marcas identitárias de suas nações. Para Rubem Cesar Fernandes, a Virgem de Aparecida não cumpre o seu papel, mas a culpa não é dela. Dá a impressão de que o título de Rainha e Padroeira do Brasil pesa excessivamente sobre os seus ombros. O texto merece uma análise mais detalhada.

Fernandes começa seu argumento a partir de um episódio ilustrativo por ocasião da visita do Papa João Paulo II ao Brasil em 1980. Um dos pontos altos dessa visita seria a consagração do Santuário e esperava-se que milhões de romeiros acorressem ao evento. No entanto, a decepção foi grande. Não mais do que umas trezentas mil pessoas, "número costumeiro para um bom domingo", apareceram para prestigiar a cerimônia. Segundo Fernandes, as expectativas se tornaram infundadas porque não levaram em conta dois aspectos importantes das romarias no Brasil: 1) os romeiros não se põem em marcha em resposta aos apelos feitos pelos guardiões do Santuário. Eles obedecem, antes, ao calendário das devoções de seus locais de origem. Os maiores números de romeiros acorrem à Aparecida em maio, outubro e dezembro. O Papa veio em julho, uma data absolutamente deslocada dos ritmos devocionais. 2) parece que a presença do Papa em Aparecida não causou grande impressão entre os católicos e estes preferiram recepcionar o Pontífice em suas próprias cidades: os cariocas no Rio, os paulistas em São Paulo, os mineiros em Belo Horizonte. O mesmo Papa, em suas duas viagens à Polônia, alcançou o clímax dessas visitas quando chegou aos pés da padroeira nacional. "O mesmo não ocorreu no Brasil, simplesmente porque a Senhora Negra de Aparecida não é portadora dos mesmos valores que a Senhora Negra de Czestochowa” (p. 87). Por aqui, os romeiros sabem que Aparecida é a capital religiosa do Brasil, mas isso não é suficiente para pô-los em movimento.

Para Fernandes, Aparecida é reconhecida como centro devocional principalmente no Centro-Sul do Brasil. Sua influência é mais forte no triângulo São Paulo, Rio de Janeiro, Minas Gerais, porém, nas demais regiões, esse santuário disputa com outros a hegemonia sobre as almas dos devotos: Bom Jesus da Lapa, 
Nossa Senhora da Conceição da Praia ou o Senhor do Bonfim, na Bahia; Padre Cícero, no nordeste; e, no norte, a Nossa Senhora de Nazaré, em Belém. A geografia religiosa do Brasil não coincide com a geografia política e econômica. Em termos de cultura não há um centro de convergência e auto identificação para qualquer coisa que se possa chamar de brasilidade e nesse caso, por este viés de análise, a religião contribui como força centrífuga.

Dos títulos atribuídos à Virgem de Aparecida - Rainha, Senhora e Mãe - o de Rainha é o mais problemático. Desde a proclamação da República, houve um esforço deliberado para transformar Aparecida em um centro nacional de devoção e romarias. Esse esforço era emoldurado pelas disputas entre o Estado republicano e a Igreja. A localização de Aparecida vinha bem a calhar: rota obrigatória desde o século XVIII para o ouro, a cana-de-açúcar, o café e a política, a cidade se prestava a se tornar também o destino "natural" e a síntese da alma brasileira atavicamente católica. Este foi o esforço do clero que via nessa forma de devoção popular um meio de resistir ao secularismo imposto pela nova ordem política. A data da coroação de Nossa Senhora, 8 de setembro de 1904, dia da Natividade, foi escolhida a propósito na tentativa de impedir um maior distanciamento entre a nacionalidade e a Igreja. Foi a imagem de Nossa Senhora que melhor qualificou a Igreja em sua reivindicação de representar a nação. A Igreja honra a imagem e a imagem carreia ondas crescentes de fiéis ao Santuário. "Essa troca contribuiu para a expansão do Santuário, o qual veio a pesar significativamente nas disputas entre as elites sobre o significado da "nacionalidade"' (FERNANDES, 1988, p. 91).

No entanto, a despeito dessa convergência dos interesses da Igreja e da devoção dos fiéis, a imagem de Nossa Senhora guarda diferentes camadas hermenêuticas (como qualquer outra imagem de devoção, diga-se). Há diferentes discursos sobre a imagem: a do devoto, a do teólogo, a do pesquisador, a dos pastoralistas. Há ainda e também a fala dos comerciantes, dos agentes de turismo, dos órgãos governamentais. São muitas as imagens que subsistem sob o Manto de Nossa Senhora e, olhando à distância, é possível afirmar que o povo e o clero 
"nunca rezaram para a mesma imagem". Esse descompasso entre o discurso erudito do clero e a devoção do povo não é exclusividade do Santuário de Aparecida, mas, antes, é o padrão que se pode observar em praticamente todos os santuários.

As diferentes datas que compõe o calendário das devoções à Virgem, retratam interesses, compreensões e apropriações que impõem dificuldades para que Nossa Senhora de Aparecida desempenhe a contento o seu papel de Rainha, diferentemente do que acontece no México e na Polônia (FERNANDES, 1988, p. 94). A data mais antiga e tradicional é o 8 de dezembro porque é o dia da Conceição. Em 1885 os bispos decidiram que a Conceição de Aparecida deveria ser celebrada no quinto domingo depois da Páscoa. Em 1904 a data foi mudada para o primeiro domingo de maio, mas havia quem quisesse que fosse no dia da Natividade. Em 1939, com claras intenções políticas e em prol de nova configuração das relações entre a Igreja e o Estado, o dia 7 de setembro foi declarado o dia de Aparecida. Mas o povo, os romeiros, os fiéis ignoraram solenemente a data. Somente em 1955 é que o dia 12 de outubro foi fixado como o dia da Rainha do Brasil.

O título de Senhora goza de maior e mais bem amada circulação entre os fiéis. Embora carregue ainda um peso senhorial, ele é menos politizado que o título de Rainha. A Senhora, a Nossa Senhora, remete às relações conhecidas do ambiente doméstico e familiar. De um lado, o título de Rainha pode ter sido uma “imposição" do polo clerical dessa devoção, principalmente após a retomada por parte da hierarquia do controle da vida religiosa dos fiéis com a chegada das congregações no final do século XIX. De outro, porém, o título de Senhora sempre esteve adstrito ao imaginário devocional do brasileiro. Nisso talvez resida o maior milagre da Virgem de Aparecida, a saber, a capacidade de conciliar em uma mesma imagem, um mesmo território, essas duas expressões do catolicismo brasileiro. A um só tempo romano e brasileiro. É essa habilidade que faz sobressair a figura materna de Nossa Senhora que estende seu manto protetor para além da própria 
Igreja. O poder de Maria transcende em muito os muros católicos. Ela se apresenta também em outras religiões, a Umbanda, o Candomblé, o Santo Daime, sempre amada e adorada.

Para Rubem Cesar Fernandes a disparidade de percepção em torno da imagem de Nossa Senhora de Aparecida colocando de um lado o "povo" e de outro lado as elites pensantes do Brasil, é de difícil equacionamento. Mesmo porque a concepção de que há um “povo”, no singular, é própria das classes dominantes que, de forma contumaz, olhando para baixo, insiste em um discurso unificador e, portanto, nivelador. O mesmo pode-se dizer da ideia de nação.

Uma noção totalizante como a de 'Nação' soa embaraçosamente elitista quando ouvida no lado de baixo da pirâmide social. O Exército, a Igreja, os políticos, alguns intelectuais têm disputado entre si o direito de falar em nome da Nação; mas o conceito não chega a convencer porque não mobiliza as massas, salvo em raras ocasiões. (FERNANDES, 1988, p. 108).

Embora estejamos conscientes de que a ideia de nação seja uma construção diária na mente e no espírito de cada indivíduo, no caso do Brasil essa ideia não chegou a se cristalizar em um imaginário comum que se sobrepusesse às diferenças

de raça, gênero, classe e mesmo religiosa. As bases da pirâmide social, quando o assunto é a cultura e a identidade nacional, tiveram curso próprio, por um lado; de outro, as próprias elites com suas disputas internas, não conseguiram formular um pensamento único sequer para si mesmas sobre esse tema.

\section{Conclusão}

Uma análise de viés funcionalista, ao gosto da escola durkheiminiana, poderia tentar enxergar na religião e nas romarias, um componente fundamental para a construção da identidade nacional. De fato, quando o objeto de estudo são grupos étnicos ou grupos de migrantes, a religião pode entrar de forma relevante na manutenção das redes de solidariedade e apoio mútuo como, por exemplo, observamos entre os migrantes recém-chegados ao Brasil (BAGGIO; PARISE; 
SANCHEZ, 2016). Pode mesmo ser ainda o elemento diferencial da identidade e de fortalecimento daqueles que migram. No entanto, se os estudos sobre a identidade ou a cultura nacional tiverem como vetor analítico a vivência religiosa em torno dos santuários e do turismo religioso que eles promovem, o horizonte de referência precisa ir além dos processos rituais (VAN GENNEP, 2011; TURNER, 1974).

Nenhum outro santuário no Brasil teve a pretensão de ser o vértice da nossa identidade a não ser o de Aparecida. Houve razões históricas, políticas e religiosas para essa pretensão, mas a devoção à Nossa Senhora, espraiada em todo o território nacional, é maior, mais rica e mais plural que aquela ordenada nos espaços do Santuário. Nenhum discurso sobre a "nação brasileira" foi, até o momento, capaz de criar uma identidade única, clara e absoluta com o Santuário de Aparecida. Os devotos têm suas próprias motivações para se porem a caminho de Aparecida e as elites, do clero ou da política, por mais condescendentes que sejam, não se ajoelharão diante da mesma Senhora.

\section{REFERÊNCIAS}

ABUMANSSUR, Edin S. Turismo religioso: ensaios antropológicos sobre religião e turismo, Campinas: Papirus, 2003.

ABUMANSSUR, Edin S. A força do mito: tensões e acomodações narrativas em torno das imagens de devoção. In: Academia Marial de Aparecida. Aparecida, 3oo anos de fé e devoção. Aparecida: Santuário/Academia Marial de Aparecida, 2017. p. 111-117.

BAGGIO, Fabio; PARISE, Paolo; SANCHEZ, Wagner Lopes. Mobilidade humana e identidades religiosas. São Paulo: Paulus, 2016.

BANDUCCI JÚNIOR, Álvaro; BARRETO, Margarita. Turismo e identidade local: uma visão antropológica. Campinas: Papirus, 2001.

BELLAH, Robert. Civil Religion in America. Dadalus, Journal of the American Academy of Arts and Sciences, Hartford, Winter, v. 96, n. 1, p. 1-21, 1967. Disponível em:

<http://www.robertbellah.com/articles_5.htm>. Acesso em: 15/o1/2018. 
CALHOUN, Craig; JUERGENSMEYER, Mark; VANANTWERPEN, Jonathan (Ed.).

Rethinking secularism. New York, Oxford University, 2011.

DONNELLY, Doris. Pilgrims and Tourists Conflicting Metaphors for the Christian Journey to God. Spirituality Today, Chicago, Spring, v. 44, n. 1, p. 20-36, 1992.

FERNANDES, Rubem Cesar. Aparecida: nossa rainha, senhora e mãe, saravá! In: SACHS, Viola et al. Brasil e Estados Unidos: religião e identidade nacional. Rio de Janeiro: Graal, 1988. p. 85-111.

HALL, Stuart. A identidade cultural na pós-modernidade. Rio de Janeiro: DP\&A, 2006.

KRIPPENDORF, Jost. Sociologia do turismo: para uma nova compreensão do lazer e das viagens. São Paulo: Aleph, 2001.

LAZZARESCHI, Noêmia. Trabalho e lazer: o turismo em questão. Revista Margem, São Paulo, n. 13, p. 127-134, jun. 2001.

LUCKMANN, Thomas. A religião invisível. São Paulo: Olho d’Água/Loyola, 2014.

PACE, Enzo. Religião e globalização. In: ORO, Ari Pedro; STEIL, Carlos Alberto (Org.).

Globalização e religião. Petrópolis, Vozes, 1997. p. 25-42.

SACHS, Viola et al. Brasil e Estados Unidos: religião e identidade nacional. Rio de Janeiro: Graal, 1988.

SAMPAIO, Jorge. Aparecida em números. In: ACADEMIA MARIAL DE APARECIDA. Aparecida, 3oo anos de fé e devoção. Aparecida: Santuário/Academia Marial de Aparecida, 2017. p 163-166.

SAYAD, Abdelmalek. Imigração ou os paradoxos da alteridade. São Paulo: Edusp, 1998.

TROELTSCH, Ernst. The social teaching of the christian churchs. London/New York: George Allen \&Unwin/The Macmillan Company, 1931.

TURNER, Victor. O processo ritual: estrutura e antiestrutura. Petrópolis: Vozes, 1974.

VAN GENNEP, Arnold. Os ritos de passagem. Petrópolis: Vozes, 2011.

VIEIRA, Dilermando Ramos. A história da devoção de Aparecida no contexto do catolicismo popular brasileiro. In: ACADEMIA MARIAL DE APARECIDA. Aparecida, 300 anos de fé e devoção. Aparecida: Santuário/Academia Marial de Aparecida, 2017. p. $45-56$. 